\title{
Inhalational Injury Management: From Intubation to Nebulized Heparin
}

\author{
Nissar Shaikh, Abdul Gafoor M. Tharayil, Ranjan Mathias, Raju Vegesna', Jimmy Thomas², Marcus Lance \\ Department of Anaesthesia, SICU, Hamad Medical Corporation, 'Department of Surgery, Hamad Medical Corporation, ${ }^{2}$ Department of Plastic Surgery, Burns Unit, \\ Hamad Medical Corporation, Doha, Qatar
}

\section{Abstract}

Inhalational injury is common during fire accidents. Upper airway injury occurs due to heat, whereas the lower airway injury is caused by chemical irritation. It causes local damage to the upper, lower airway, and lung parenchyma leading to erythema, bronchorrhea, edema, airway obstruction, and surfactant loss. Plasma leakage occurs due to a storm of pro-inflammatory markers and vascular leak, with fibrin deposition, leading to formation of airway cast and debris increasing the risk of airway obstruction. Systemic complications occur due to anoxia, carbon monoxide, and hydrogen cyanide poisoning. An inhalational injury should be suspected in patients with a history of exposure to flames and in those who are entrapped in a closed compartment during the fire. Facial burns, singed facial or nasal hair, stridor, and carbonaceous sputum should raise suspicion of high index of inhalational injury. Severity of inhalational injury can be graded using 133 Xenon (radioisotope) study, bronchoscopy, computerized tomography findings, or virtual endoscopy. In the management of inhalational injury, keeping airway patent and secured is of vital importance. According to the advanced trauma life support principles, these patients should be intubated early, but as per the recent literature, it may not be necessary to intubate all inhalation injury patients. Adjuvant therapy includes bronchodilators, mucolytics, and beta-agonists. Nebulized heparin is found to be useful as it breaks and prevents new clot formations in the airway without any systemic anticoagulant effects. Inhalational injury is an independent risk factor for increase in mortality in burn patients.

Keywords: Airway edema, bronchoscopy, carbon monoxide, chemical irritation, computerized tomography, endotracheal intubation, heparin nebulization, inhalational injury

\section{INTRODUCTION}

Burn injuries are common, and they are the fourth frequent results of trauma in the world. In burn patients, inhalational injury is an independent factor contributing to increased morbidity and mortality. ${ }^{[1]}$ Inhalational injury is recognized as an important clinical concern and had increased awareness after the fatal coconut Grove nightclub fire in 1942, where 492 people died within 15 minutes of fire. Fatalities in this incidence occurred as people were trapped in burning fire and smoke without exit doors, without escape routes, and doors were locked. The night club was full of decorative inflammable structures generating toxic chemicals in combustion. ${ }^{[2]}$ In the current review, we will discuss inhalational injury under the following subheadings.

\section{DefinITION}

Inhalational injury is damage to the upper airway, the tracheobronchial tree, and the lung parenchyma because of

\begin{tabular}{|l|l|}
\hline \multicolumn{2}{|c|}{ Access this article online } \\
\hline Quick Response Code: & Website: \\
& www.ijrconline.org \\
& \\
\end{tabular}

thermal injury or chemical irritation from the agents generated during fire and combustion. ${ }^{[2]}$

\section{EPIDEMIOLOGY}

Inhalational injury affects significant percentage of burn patients and has an impact on morbidity and mortality; hence, it was designated in the past decade as one of the top research priorities in burns. ${ }^{[3]}$ Interestingly, the risk of inhalation injury is associated with total body burn area. While a burn area of $20 \%$ correspond to a $2.2 \%$ chance of inhalation injury, an injury of $99 \%$ burn will have $14 \%$ chance of inhalational injury. ${ }^{[4]}$ The

Address for correspondence: Dr. Abdul Gafoor M Tharayil, Department of Anaesthesia, SICU, Hamad Medical Corporation, Doha, Qatar. E-mail: agafoormt@gmail.com

This is an open access journal, and articles are distributed under the terms of the Creative Commons Attribution-NonCommercial-ShareAlike 4.0 License, which allows others to remix, tweak, and build upon the work non-commercially, as long as appropriate credit is given and the new creations are licensed under the identical terms.

For reprints contact: reprints@medknow.com

How to cite this article: Shaikh N, Tharayil AM, Mathias R, Vegesna R, Thomas J, Lance M. Inhalational injury management: From intubation to nebulized heparin. Indian J Respir Care 2020;9:171-7.

Received: 09-02-2020

Accepted: $13-04-2020$ Published: 05-06-2020 
Shaikh, et al.: Inhalational injury management: From intubation to nebulized heparin

overall-reported incidence of inhalational injury ranges from $10 \%$ to $20 \%$ of all burn patients. ${ }^{[5]}$ A lower rate of inhalation injury is reported from Israel at $1.5 \%$, while China reported $8 \%$ and the USA $19.5 \% .{ }^{[6]}$ The older study by Shirani et al. reported a higher incidence of inhalation injury of 35\% ${ }^{[7]}$ Surprisingly, a recent study from the Korean peninsula also reported a much higher incidence of $43 \%$ inhalational injury in burn patients. ${ }^{[1]}$ Sheridan reported a decrease in inhalational injury incidence to $5 \%$ due to an increased use of smoke detection alarms and other preventive measures. ${ }^{[8]}$

\section{Pathophysiology}

As part of the burn injury but also as a single standing injury, inhalational injury causes upper and lower airway and lung parenchymal injuries, as well as systemic complications. ${ }^{[9,10]}$ Generally, the systemic injuries cover ischemic damage caused by anoxia, carbon monoxide (CO), and hydrogen cyanide toxicity. Combustion and oxidation during a fire quickly consume oxygen available in the environment; thus, the inhalation of oxygen deficient air during the fire can cause anoxia and hypoxic brain injury. ${ }^{[8]}$

$\mathrm{CO}$ is a colorless and odorless gas as a result of incomplete burning of fossil fuels. It shows a 200 times higher affinity to hemoglobin than oxygen and causes immediate death in patients with burn and inhalational injuries. ${ }^{[1]} \mathrm{CO}$ shifts the oxyhemoglobin dissociation curve to the left, impairing the release of oxygen at the tissues and impairing its utilization in the tissues by the mitochondria leading to tissue hypoxia. CO levels of $3 \%$ in nonsmokers and $15 \%$ in smokers should be warning for the toxicity. Ten percentage to $20 \%$ CO levels in humans cause nausea and headache, $20 \%-30 \%$ are associated with muscle weakness and $\mathrm{CO}$ levels, and 30\%-50\% will lead to cardiac ischemia and unconsciousness. ${ }^{[8]}$ Hydrogen cyanide toxicity occurs in burn patients due to the combustion of synthetic polymerases such as polymers, plastic, foam, nylon silk, and wool. The substance is easily absorbed by inhalation in the small airways and alveoli. Due to its high toxicity, it is one of the causes of immediate death in burn patients. ${ }^{[8,12]}$

In contrast, local inhalational injuries occur directly due to heat or chemical injury to the tracheobronchial tree and/or lung parenchyma. Upper airway injury occurs due to the thermal damage, apart from steam injuries as heat dissipates in the upper airway with wider area and the protective effect of glottis closure which prevents progress of heat to the lower airways. ${ }^{[13]}$ The immediate manifestations of thermal injuries are erythema, ulceration, and edema. The aggressive fluid therapy used for the general burn management adds to early edema formation and airway compromise. In addition, the facial and neck burns might cause distortion of normal anatomy and external compression of the upper airways leading to double hit in airway compromise. Apart from all these, the acute inflammation and damage of ciliary function will impair the physiological clearance of airway leading to an increased risk of bacterial infections in patients with inhalational injury. ${ }^{[14,15]}$

Unlike the upper airway, lower airway injury occurs due to the chemical irritation produced by inhaling the toxic fumes generated during the burning of decorative material, foam, and plastics. These toxic fumes contain halogen acids, formaldehydes, and unsaturated aldehydes. Their toxicity leads to denuding of respiratory mucosa causing sloughing. Damaged nerve endings in the mucosa will induce profuse release of pro-inflammatory markers and secretions. The combination of local cellular damage and loss of hypoxic pulmonary vasoconstriction leads to increased bronchial blood flow by multiples within a few minutes of the inhalational injury. ${ }^{[5,14,15]}$ Further to it, the damage and gaps in the injured bronchial epithelium generate reactive oxygen species causing leakage of plasma and fluids from the intravascular compartment into the bronchoalveolar space. The epithelial inhalational injury causes loss of surfactant and ciliary function in combination with fibrin and burn debris. This mixture forms airway clots together with soot. This obstructing material from lower airways causes the "black-sputum" (melanoptysis). ${ }^{[16]}$ Finally, it leads to lower airway lung collapse, ventilation perfusion mismatch, and increased risk of pneumonia. ${ }^{[1,8,9]}$ Due to the above-mentioned changes, there is a ventilation disparity within the lungs. The unaffected portions of the lungs will be hyperventilated producing a compensatory emphysema. In the presence of a partial lung collapse, it may need higher tidal volume or inspiratory pressure to inflate the collapsed lungs leading to the injury to emphysematous, otherwise normal lungs, causing barotrauma or/and volutrauma. ${ }^{[1,17]}$

\section{Classification and Grading}

Unfortunately, there is a lack of standardized and validated methods for scoring the severity of inhalational injury. Currently, there is an ongoing trial for assessing the severity of inhalational injury based on clinical, biochemical, and bronchoscopic parameters. (Clinical Trials.govidentifier NCT 01194024).

Shirani et al. proposed the following three grades of inhalational injury [Table 1]: (1) patients without inhalational injury, (2) patients with inhalation injury on ${ }^{133}$ xenon study only, and (3) patients having inhalational injury on bronchoscopy. ${ }^{[7]}$ Disadvantage of bronchoscopy is its invasiveness.

Endorf and Gamelli propose an abbreviated injury score based on bronchoscopic findings. The advantage of this grading system is that it is easy to determine using bronchoscopy. However, a major disadvantage is that it will not give

\begin{tabular}{ll}
\hline Table 1: & Shirani's grading \\
\hline Grades & Characteristics \\
\hline Grade 1 & Patients without inhalational injury \\
Grade 2 & Patients with inhalation injury on 133 xenon study \\
Grade 3 & Patients having inhalational injury on bronchoscopy \\
\hline
\end{tabular}


an idea of segmental bronchioles and lung parenchymal injury [Table 2] ${ }^{[18]}$

The RADS score is a computerized tomography (CT) evaluation in 1-cm axial slices which helps in estimating the extent of an inhalational injury [Table 3]. ${ }^{[19]}$

The disadvantages of RADS score are the timing of performance of CT scan and interpretation of these scans in the absence of bronchoscopy. ${ }^{[5]}$

A new promising technique, the virtual endoscopy, uses three-dimensional reconstructions of CT scan, presented in a way that the investigator virtually navigates through the lungs as if performing a bronchoscopy evaluation [Figure 1]. It might be useful in detecting the anatomical defects and discontinuations after an injury, but this technique does not allow the assessment of mucosal changes. ${ }^{[20]}$

Taking the given advantages and disadvantages of these approaches into account, it might be wise to combine them in a scoring system. As such, it could be supported by clinical parameters to evaluate the severity and the course of an injury.

\section{Diagnosis}

A high index of suspicion is essential in the diagnosis of inhalational injury. Initial information obtained from the site of burn will give vital clues of inhalational injuries. This includes exposure to the burn flame, smoke or chemicals, duration of the exposure, exposure in the enclosed compartment, duration of entrapment, and loss of consciousness during the burns. ${ }^{[1,5]}$

In the physical examination, facial burns, singed facial or nasal hairs, carbonaceous deposits or soot on the face or in the sputum and/or signs of airway obstruction, stridor, and

\begin{tabular}{lll}
\hline Table $2:$ & Abbreviated injury score & \\
\hline Grade & Description & Class \\
\hline 0 & $\begin{array}{l}\text { Absence of edema, erythema, bronchorrhea, } \\
\text { carbonaceous deposits or obstruction }\end{array}$ & No injury \\
1 & $\begin{array}{l}\text { Minor patchy areas of erythema, bronchorrhea, } \\
\text { carbonaceous deposits or obstruction }\end{array}$ & Mild injury \\
2 & $\begin{array}{l}\text { Moderate degree of erythema, bronchorrhea, } \\
\text { carbonaceous deposits or obstruction }\end{array}$ & $\begin{array}{l}\text { Moderate } \\
\text { injury } \\
\text { Severe } \\
\text { injury }\end{array}$ \\
3 & $\begin{array}{l}\text { Severe inflammation with friable, copious } \\
\text { bronchorrhea, carbonaceous deposits or } \\
\text { obstruction }\end{array}$ & $\begin{array}{l}\text { Massive } \\
\text { Evidence of mucosal sloughing, necrosis, } \\
\text { endoluminal obstruction }\end{array}$ \\
\hline
\end{tabular}

\begin{tabular}{ll}
\hline Table 3: Radiologist's score & \\
\hline Score & CT findings \\
\hline 0 & Normal \\
1 & Increased interstitial markings \\
2 & Ground glass appearance \\
3 & Patchy consolidations \\
\hline CT: Computerized tomography &
\end{tabular}

hoarseness of voice might give a hint about the probability and the extent of an inhalational injury. ${ }^{[5,18]}$

The severity of inhalational injury can be assessed clinically and by laboratory measurement of the arterial blood gas (e.g. CO-Hb). Finally, the diagnosis will be confirmed by above-mentioned severity scores. As a rule of thumb, the older or bedridden and/or extensive burn patients are at higher risk of inhalational injury due to the extended period of exposure in burn environment. ${ }^{[7]}$ The quality of the combusted material could raise the suspicion of lower airway damage (e.g. toxicity of burned plastic).

\section{Management}

The management of inhalational injury will be discussed from initial assessment, intubation, and to newer therapeutic interventions.

\section{Initial management and disposition}

The priority should be to rescue the burn patients from the scene early, which will effectively decrease the exposure to flames and toxic chemicals. In the initial assessment, follow the primary survey initiatives. Follow A (airway), B (breathing), $\mathrm{C}$ (circulation), D (disability), E (exposure) pattern and treat the life-threatening condition before proceeding to the next step. Burn patients with conditions shown in Table 4 should be admitted for monitoring in the hospital.

All patients with inhalational injury should be supplemented with $100 \%$ oxygen. In case of CO intoxication, $100 \%$ oxygenation should be continued for 6 h. ${ }^{[21]}$

\section{Securing the airway}

Proper evaluation and securing of airway in a patient with inhalational injury are of vital importance. The presence of inhalational injury does not dictate the need for intubation, but the loss of airway control in these patients is disastrous. Up to $80 \%$ of these patients require endotracheal intubation to secure their airway. ${ }^{[22]}$ Intubation should be done with a large diameter endotracheal tube (ETT) to ease the draining of secretions and frequent bronchoscopy. The ETT should be secured properly, as reintubation can be life-threatening

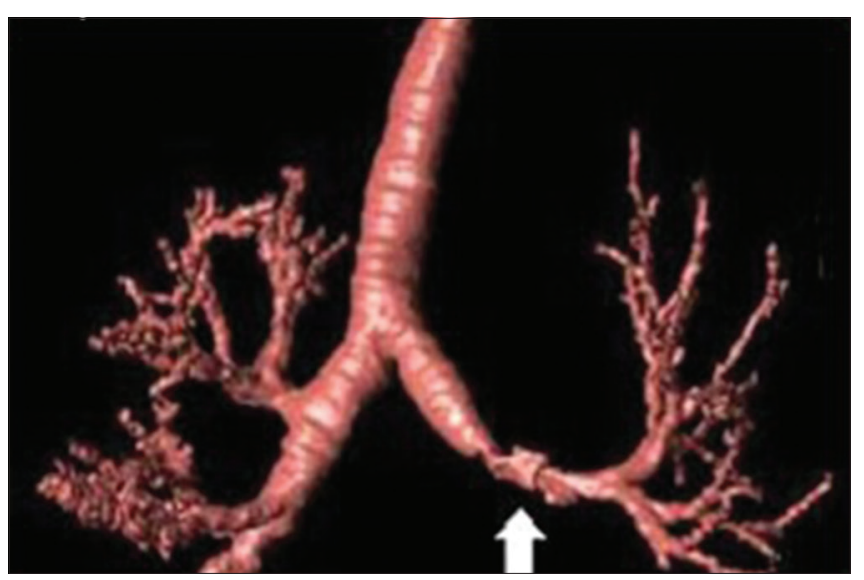

Figure 1: Virtual endoscopy showing left bronchial narrowing 
in these patients. ${ }^{[22]}$ In patients with inhalational injury, the common deciding factors for early intubation are facial and neck burns, oropharyngeal edema, stridor, respiratory distress, and hypoventilation. Interestingly, Mackie et al. found an increased use of mechanical ventilation from 1997 to 2006 (76\%) compared to from 1987 to 1996 (38\%) despite decrease in the incidence of inhalational injury from $34 \%$ to $27 \%{ }^{[23]}$ The authors attributed this increase to the practice of advanced trauma life support principles in the 1990s. Furthermore, they found that mechanical ventilation was an independent risk for mortality in burn patients. ${ }^{[23]}$

Klein et al. reported that $33 \%$ of burn patients who were intubated early could be extubated within 1 day and $65 \%$ by day 2. ${ }^{[24]}$ Endotracheal intubation and ventilation is not free from complications. Being an invasive procedure, it can cause tracheal injuries, loss of airway, ventilator-associated events, and increased chances of death. Romanowski et al. found that one-third of intubations in burn patients with suspected inhalational injury were unnecessary and the risk to these patients outweighed the benefits. ${ }^{[25]}$ Recently, Orozco-Pelaez also concluded in their review of intubation in patients with inhalational injury that there is no conclusive clinical evidence to justify routine prophylactic intubations in these patients. ${ }^{[10]}$

The best practice seems to be to keep the airway secured till an intervention (bronchoscopy or imaging studies) gives clear information on the airway patency. Our institutional practice for the patients with facial and neck burn injuries is, if not intubated by emergency medical service personnel at the scene of the incident, we primarily observe the patients for airway compromise instead of routine intubation.

Ventilatory management of intubated inhalational injury patients is not standardized, and no single mode of ventilation is used consistently. In this sense, the best way might be to use the mode with which the treating physician is familiar with. Peck and Koppelman suggest that in these patients, pressure-controlled, lung protective ventilation is the best mode of ventilation, as it prevents biotrauma, barotrauma, and volutrauma. ${ }^{[26]}$ A recently published pediatric burn study showed that higher tidal volume ventilation had fewer days on ventilator and lower rate of acute respiratory distress syndrome (ARDS) ${ }^{\left[{ }^{[2]}\right]}$ The best practice to manage the patients complicated with ARDS is to follow "ARDS12" parameters in the management. ${ }^{[28]}$

The readiness for extubation of these intubated inhalation injury patients should be assessed by the parameters which are described in following Table 5.

A few centers do an elective early tracheostomy in the patients with inhalational injury. However, there is no statistically significant difference in length of stay, occurrence of pneumonia, and duration of ventilation between intubated and tracheostomized burn patients. ${ }^{[29]}$ The best practice is to consider tracheostomy in these patients if extubation attempts failed thrice or if the patients are intubated for more than 3 weeks. ${ }^{[29]}$

\author{
Table 4: Indication for hospital admission in burn patients \\ Entrapment during burns \\ Syncope/hypoxia \\ Carbonaceous deposits and/or sputum \\ High lactate or metabolic acidosis \\ Carboxyhemoglobin levels $>15 \%$ \\ Facial burns and/or bronchospasm
}

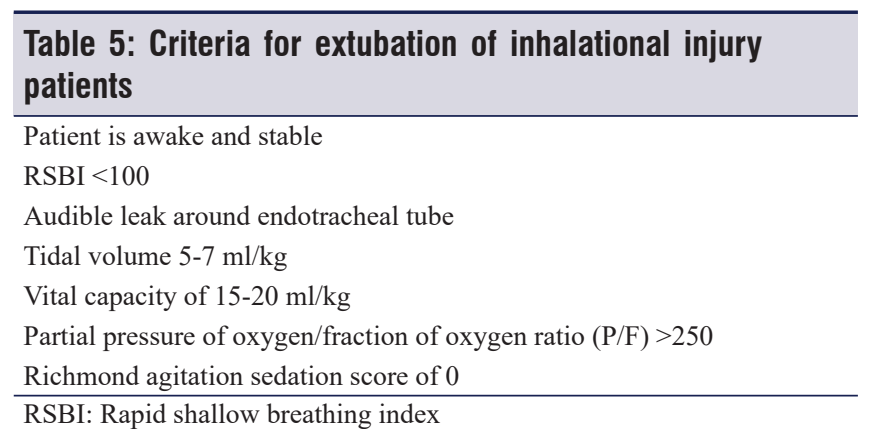

\section{Fluid therapy}

Many physicians advise to restrict the fluid resuscitation in inhalational injury patients to decrease the airway edema formation, but this hypothesis proved to cause hypoperfusion, shock, and increased chances of death. On the contrary, fluid overload is also dangerous, as it can lead to pulmonary edema, compartment syndrome, shock, and death. ${ }^{[1,7,8,30]}$

Hence, fine titration of fluid therapy in these patients is essential, which is possible with the use of advanced hemodynamic monitoring parameters.

\section{Bronchoalveolar lavage}

Bronchoalveolar lavage with saline in inhalational injury patients complicated by pneumonia resulted in a significant shorter intensive care unit and hospital stay, reduced cost, and reduced mortality. ${ }^{[31]}$

\section{Bronchodilators}

Bronchodilators relax the bronchial smooth muscles, stimulate mucociliary clearance, decrease airflow resistance, and improve the dynamic compliance in inhalation injury patients with bronchospasm. ${ }^{[5]}$ Various aerosolized bronchodilators such as albuterol, racemic epinephrine, and beta-agonists are frequently used in inhalation injury patients. ${ }^{[5]}$

\section{Mucolytics}

Mucolytics augment expectoration and breakdown the airway casts. Hence, they are the core therapeutic agents in patients with inhalational injury. N-acetylcysteine (NAC), a commonly used mucolytic agent in these patients, breaks the disulfide binds in mucus causing lysis. ${ }^{[32]}$ NAC causes bronchial irritation and hence should be used in combination with the

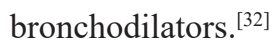

\section{Anticoagulants}

Anticoagulants such as heparin and heparinoids were tried in the management of the inhalational burn injury. Nebulized 
heparin acts by breaking down the fibrin casts and preventing further formation of casts without any systemic anticoagulation effects. This was demonstrated in both human and animal studies.

Nebulized heparin and NAC were found to reduce reintubation and mortality rate as per a retrospective study earlier in 1998 conducted by Desai et al. ${ }^{[33]}$ in pediatric patients. This study included 90 pediatric patients who had bronchoscopically diagnosed inhalation injury requiring ventilatory support, admitted between 1985 and 1995. Forty-seven children admitted between 1990 and 1994 received 5000 units of heparin and $3 \mathrm{ml}$ of a $20 \%$ solution of aerosolized NAC, every 4 hours for the first 7 days after the injury. The rest of the children admitted between 1985 and 1989 who did not receive this therapy acted as controls. In another retrospective study by Miller et al., 30 patients, with bronchoscopically demonstrated inhalational burns within 48 hours of admission, received combined therapy with nebulized heparin and NAC. They showed improved lung compliance, less pulmonary edema, and lesser airway obstruction when compared with historical controls. ${ }^{[34]}$ More recently, Ashraf et al. ${ }^{[35]}$ used inhaled unfractionated heparin at a dose of $10,000 \mathrm{IU}$ in $3 \mathrm{~mL}$ of $0.9 \%$ normal saline alternating with $3 \mathrm{~mL}$ of $20 \%$ NAC two hourly, started $48 \mathrm{~h}$ after admission, and continued for 7 days. Bronchoscopy was performed on the $5^{\text {th }}$ day of admission and demonstrated a significant improvement in airway edema and a resolution of soot.

McIntire et al.$^{[36]}$ conducted a retrospective, case-control study designed to evaluate efficacy and safety of nebulized heparin administered to mechanically ventilated adults admitted within $48 \mathrm{~h}$ of confirmed inhalational burn injury. Nebulized heparin 10,000 units was administered Q4H for 7 days, or until extubation, alternating with albuterol and a mucolytic. They found that nebulized heparin in combination with beta-agonist and mucolytic decreased the duration of mechanical ventilation and increased the ventilator-free days.

El-Sharnouby et al..$^{[37]}$ conducted a prospective single-center randomized control study comparing various doses of nebulized heparin. They compared two-dosage regimens; Group H5 received nebulized heparin sulfate 5,000 IU, and group $\mathrm{H} 10$ received nebulized heparin sulfate 10,000 IU four hourly alternating with NAC every 2 h. Primary outcome was lung injury score assessed daily for 7 days. Secondary outcomes were duration of mechanical ventilation, coagulation profile, length of ICU stay, and mortality. They found that a dose of 10000 units every $4 \mathrm{~h}$ was more effective in decreasing lung injury score and duration of mechanical ventilation, though there was no difference in mortality between the groups.

Miller et al., ${ }^{[6]}$ performed a systematic review of preclinical and clinical studies which used inhaled or aerosolized anticoagulants. They found that both in preclinical and clinical settings, inhaled heparin improved mortality and reduced morbidity without causing significant systemic effects of anticoagulation.
In a more recent review by Zieliński et al., ${ }^{[4]}$ they compared different trials with varying dose regimens of nebulized heparin among different age groups and found that the therapy has variable effectiveness and impact on the incidence of pneumonia, lung injury, mechanical ventilation, and mortality. There was no significant bleeding risk in adults with commonly used dosage of 10000 units q4 hourly which appears to be the more effective dosage regimen.

As of now, there are no well-designed, multicenter, randomized, prospective trials on usefulness of nebulized heparin on inhalational burns. However, the available evidence suggests that this therapy is a promising and safe option in this potentially lethal injury with significant morbidity and mortality.

\section{Outcome}

The overall reported mortality in inhalational injury patients ranges from $10 \%$ to $30 \%$ and it increases with patients' age and percentage of burn..$^{[1,38]}$

Detection of inhalation injury on bronchoscopy was associated with a 8.3 fold increased risk of pneumonia, ARDS, and death. Higher RADS score is associated with a 12.7 fold increased risk of pneumonia, ARDS, and death. ${ }^{[5]}$

Inhalational injury is an independent predictor of increased mortality in burn patients. The increased severity of inhalational injury was associated with an increased in mortality. ${ }^{[39]}$

You et al. found that the presence of inhalation injury and carboxyhemoglobin levels did not predict the mortality. ${ }^{[40]}$ Kim et al. reported a higher mortality of $25.6 \%$ in inhalational injury patients and factors that increased the mortality were partial pressure of oxygen/fraction of oxygen ratio, percentage of burn, and patient's age. ${ }^{[1]}$ An older study from Egypt reported higher mortality of $33 \%$, whereas in a Saudi study, mortality of inhalation injury was $8 \% .^{[40]}$

\section{ConcLusion}

Inhalational injury causes damage to the airway and lung parenchyma due to thermal burn, chemical irritation with or without systemic toxicity. The incidence of inhalation injury ranges from 10 to $20 \%$, and the use of detection alarms will further decrease the incidence of inhalation injury. Local pathophysiological changes in upper and lower airway and lung parenchyma are due to direct effect of heat or by chemical irritation of toxic fumes during the fire. The net changes due to inhalational injury are airway inflammation, increased secretions, airway compromise due to edema, and deposition of clots and soot causing airway obstruction. The systemic toxicity is due to the $\mathrm{CO}$ and hydrogen cyanide poisoning causing immediate deaths or hypoxic brain injury. High index of suspicion for inhalation injury should be made from the history and physical findings of burn patients. The severity of inhalation injury can be graded from no injury to massive injury by bronchoscopy, which also has therapeutic 
Shaikh, et al.: Inhalational injury management: From intubation to nebulized heparin

effects by clearing the airway. Patient's airway management is vital in inhalation injury. From mid-1990s directed by the advanced trauma life support guidelines, early intubation is performed in these patients. In recent studies, majority of these early intubations were found to overweigh the risk than the benefits. Fluid therapy should be managed with dynamic advanced hemodynamic monitoring parameters. Heparin nebulization along with the mucolytics and bronchodilators help in improvement of inhalational injury by airway clearance and relieving the bronchospasm. Inhalational injury is the third factor predicting the mortality in burn patients after percentage of burns and patient's age. Although the older studies reported higher mortality in inhalational injury patients, the mortality ranges from $10 \%$ to $30 \%$.

Early and prompt intervention in selected patients with advanced investigations and therapy contributes to the improvement of mortality and successful outcome of patients with inhalational burn injuries.

\section{Financial support and sponsorship}

Nil.

\section{Conflicts of interest}

There are no conflict of interest.

\section{RefEREnCES}

1. Kim Y, Kym D, Hur J, Yoon J, Yim H, Cho YS, et al. Does inhalation injury predict mortality in burns patients or require redefinition? PLoS One 2017;12:e185195.

2. Lee KC, Joory K, Moiemen NS. History of burns: The past, present and the future. Burns Trauma 2014;2:169-80.

3. Greenhalgh DG, Saffle JR, Holmes JH $4^{\text {th }}$, Gamelli RL, Palmieri TL, Horton JW, et al. American Burn Association consensus conference to define sepsis and infection in burns. J Burn Care Res 2007;28:776-90.

4. Zieliński M, Wróblewski P, Kozielski J. Is inhaled heparin a viable therapeutic option in inhalation injury? Adv Respir Med 2019;87:184-8.

5. Walker PF, Buehner MF, Wood LA, Boyer NL, Driscoll IR, Lundy JB, et al. Diagnosis and management of inhalation injury: an updated review. Crit Care 2015;19:351.

6. Miller AC, Elamin EM, Suffredini AF. Inhaled anticoagulation regimens for the treatment of smoke inhalation-associated acute lung injury: a systematic review. Crit Care Med 2014;42:413-9.

7. Shirani KZ, Pruitt BA Jr., Mason AD Jr. The influence of inhalation injury and pneumonia on burn mortality. Ann Surg 1987;205:82-7.

8. Sheridan RL. Fire-Related Inhalation Injury. $N$ Engl $J$ Med 2016;375:464-9.

9. Toussaint J, Singer AJ. The evaluation and management of thermal injuries: 2014 update. Clin Exp Emerg Med 2014;1:8-18.

10. Orozco-Pelaez YA. Airway burn or inhalation injury: Should all patients be intubated? Rev Colomb Anestesiol 2018;46:26-31.

11. Centers for Disease Control and Prevention (CDC). Carbon monoxide-related deaths-United States, 1999-2004. MMWR Morb Mortal Wkly Rep 2007;56:1309-12.

12. Barillo DJ, Goode R, Esch V. Cyanide poisoning in victims of fire: Analysis of 364 cases and review of the literature. J Burn Care Rehabil 1994;15:46-57.

13. Moritz AR, Henriques FC, McLean R. The Effects of Inhaled Heat on the Air Passages and Lungs: An Experimental Investigation. Am J Pathol 1945;21:311-31.

14. Rehberg S, Maybauer MO, Enkhbaatar P, Maybauer DM, Yamamoto Y, Traber DL. Pathophysiology, management and treatment of smoke inhalation injury. Expert Rev Respir Med 2009;3:283-97.

15. Chao KY, Lin YW, Chiang CE, Tseng CW. Respiratory Management in
Smoke Inhalation Injury. J Burn Care Res 2019;40:507-12.

16. Demling RH. Smoke inhalation lung injury: An update. Eplasty 2008;8:e27.

17. Seeger W, Stöhr G, Wolf HR, Neuhof H. Alteration of surfactant function due to protein leakage: Special interaction with fibrin monomer. J Appl Physiol (1985) 1985;58:326-38.

18. Endorf FW, Gamelli RL. Inhalation injury, pulmonary perturbations, and fluid resuscitation. J Burn Care Res 2007;28:80-3.

19. Park MS, Cancio LC, Batchinsky AI, McCarthy MJ, Jordan BS, Brinkley WW, et al. Assessment of severity of ovine smoke inhalation injury by analysis of computed tomographic scans. J Trauma 2003;55:417-27.

20. Ganaw AE, Ehfeda M, Shaikh N. Role of Virtual Endoscopy and 3-D Reconstruction in Airway assessment in critically ill patients: In Book Virtual Endoscopy and 3D Reconstruction in the Airways/By Dr Nabil Sallick/. London: Tech Publishers; 2019.

21. Buckley NA, Juurlink DN, Isbister G, Bennett MH, Lavonas EJ. Hyperbaric oxygen for carbon monoxide poisoning. Cochrane Database Syst Rev 2011;4:CD002041.

22. Rue LW $3^{\text {rd }}$, Cioffi WG, Mason AD Jr., McManus WF, Pruitt BA Jr. The risk of pneumonia in thermally injured patients requiring ventilatory support. J Burn Care Rehabil 1995;16:262-8.

23. Mackie DP, van Dehn F, Knape P, Breederveld RS, Boer C. Increase in early mechanical ventilation of burn patients: An effect of current emergency trauma management? J Trauma 2011;70:611-5.

24. Klein MB, Nathens AB, Emerson D, Heimbach DM, Gibran NS. An analysis of the long-distance transport of burn patients to a regional burn center. J Burn Care Res 2007;28:49-55.

25. Romanowski KS, Palmieri TL, Sen S, Greenhalgh DG. More Than One Third of Intubations in Patients Transferred to Burn Centers are Unnecessary: Proposed Guidelines for Appropriate Intubation of the Burn Patient. J Burn Care Res 2016;37:e409-14.

26. Peck MD, Koppelman T. Low-tidal-volume ventilation as a strategy to reduce ventilator-associated injury in ALI and ARDS. J Burn Care Res 2009;30:172-5.

27. Sousse LE, Herndon DN, Andersen CR, Ali A, Benjamin NC, Granchi $\mathrm{T}$, et al. High tidal volume decreases adult respiratory distress syndrome, atelectasis, and ventilator days compared with low tidal volume in pediatric burned patients with inhalation injury. J Am Coll Surg 2015;220:570-8.

28. Shaikh N, Tharayil AM, Chanda AH, Ahmed Ganaw AE, Riaz MS, Hubertus Rohrig SA, et al. Acute respiratory distress syndrome in pregnancy and peripartum: Facts and figures. Indian J Respir Care 2020;9:12-9.

29. Saffle JR, Morris SE, Edelman L. Early tracheostomy does not improve outcome in burn patients. J Burn Care Rehabil 2002;23:431-8.

30. Foncerrada G, Culnan DM, Capek KD, González-Trejo S, Cambiaso-Daniel J, Woodson LC, et al. Inhalation Injury in the Burned Patient. Ann Plast Surg 2018;80:S98-S105.

31. Carr JA, Phillips BD, Bowling WM. The utility of bronchoscopy after inhalation injury complicated by pneumonia in burn patients: results from the National Burn Repository. J Burn Care Res 2009;30:967-74.

32. Carr JA, Crowley N. Prophylactic sequential bronchoscopy after inhalation injury: results from a three-year prospective randomized trial. Eur J Trauma Emerg Surg 2013;39:177-83.

33. Desai MH, Mlcak R, Richardson J, Nichols R, Herndon DN. Reduction in mortality in pediatric patients with inhalation injury with aerosolized heparin/N-acetylcystine [correction of acetylcystine] therapy. J Burn Care Rehabil 1998;19:210-2.

34. Miller AC, Rivero A, Ziad S, Smith DJ, Elamin EM. Influence of nebulized unfractionated heparin and $\mathrm{N}$-acetylcysteine in acute lung injury after smoke inhalation injury. J Burn Care Res 2009;30:249-56.

35. Ashraf U, Bajantri B, Roa-Gomez G, Venkatram S, Cantin A, Diaz-Fuentes G. Nebulized heparin and $\mathrm{N}$-acetylcysteine for smoke inhalational injury: A case report. Medicine (Baltimore) 2018;97:e638.

36. McIntire AM, Harris SA, Whitten JA, Fritschle-Hilliard AC, Foster DR, Sood R, et al. Outcomes Following the Use of Nebulized Heparin for Inhalation Injury (HIHI Study). J Burn Care Res 2017;38:45-52.

37. El-Sharnouby NM, Eid HE, Abou Elezz NF, Aboelatta YA. Heparin/ $\mathrm{N}$-acetylcysteine: an adjuvant in the management of burn inhalation 


\section{Shaikh, et al:: Inhalational injury management: From intubation to nebulized heparin}

injury: a study of different doses. J Crit Care 2014;29:182.e1-4.

38. You K, Yang HT, Kym D, Yoon J, HaejunYim, Cho YS, et al. Inhalation injury in burn patients: Establishing the link between diagnosis and prognosis. Burns 2014;40:1470-5.
39. Hassan Z, Wong JK, Bush J, Bayat A, Dunn KW. Assessing the severity of inhalation injuries in adults. Burns 2010;36:212-6.

40. Helbawy RH, Ghareeb FM. Inhalation injury as a prognostic factor for mortality in burn patients. Ann Burns Fire Disasters 2011;24:82-8. 